\title{
Características de Plantas de Cultivares de Arroz Irrigado Relacionadas À Habilidade Competitiva com Plantas CONCORRENTES ${ }^{1}$
}

\author{
Characteristics of Flooded Rice Cultivar Plants Related to Competitive Ability Against Weeds \\ Concurrent Plants
}

FLECK, N.G. ${ }^{2}$, BALBINOT JR., A.A. ${ }^{3}$, AGOSTINETTO, D. ${ }^{3}$ e VIDAL, R.A. ${ }^{2}$

\begin{abstract}
RESUMO - Plantas que apresentam rápido crescimento tendem a ocupar precocemente nichos disponíveis, utilizando o espaço de suas vizinhas. Em geral, esses vegetais adquirem prioridade na utilização dos recursos do meio. O objetivo deste trabalho foi avaliar variações em características de crescimento de cultivares de arroz irrigado. Para isso, conduziu-se um experimento em campo na estação de crescimento de 2000/2001, em Cachoeirinha-RS. Investigou-se o comportamento de oito cultivares de arroz, cultivados em presença e ausência de plantas de arroz do cultivar EEA 406, simulando infestação de arroz-vermelho, estabelecida com densidade média de 30 plantas $\mathrm{m}^{-2}$. Entre 15 e 60 dias após a semeadura (DAS), avaliouse a evolução de área foliar, estatura e massa aérea das plantas de arroz. Com esses dados, calcularam-se razão de área foliar (RAF), taxa de crescimento relativo (TCR) e taxa de assimilação líquida (TAL) dos cultivares. Os cultivares Ligeirinho e XL 6 apresentaram elevadas velocidades de ganho em área foliar, estatura e massa aérea; com isso, alcançaram as maiores coberturas do solo, juntamente com o cultivar IR 841. Por outro lado, os cultivares Bluebelle e Formosa mostraram lento crescimento absoluto no período avaliado, mas, em geral, apresentaram os maiores valores para TCR e TAL.
\end{abstract}

Palavras-chave: competição, interferência, manejo cultural de plantas daninhas, velocidade de crescimento.

\begin{abstract}
Fast-growing plants tend to occupy available niches utilizing these spaces ahead of their neighbors. In general, these plants have priority over others in the use of environmental resources. The objective of this research was to evaluate variations in growth characteristics of flooded rice cultivars. A field experiment was carried out during the 2000/01 summer season, in Cachoeirinha, RS, Brazil. The behavior of eight rice cultivars, grown in the absence or presence of the EEA 406 rice genotype was investigated, simulating a red rice infestation, established at an average density of 30 plants $\mathrm{m}^{2}$. From 15 to 60 days after seeding (DAS), variations in leaf area, plant height, and dry weight of rice plants were evaluated. The data were used to calculate leaf area rate (LAR), relative growth rate (RGR), and net assimilation rate (NAR) of the cultivars. The cultivars Ligeirinho and XL 6 presented the fastest increments in leaf area, plant height, and dry weight, reaching the highest soil cover values, together with the cultivar IR 841. On the other hand, cultivars Bluebelle and Formosa showed slow absolute growth during the evaluated period, even though presenting the highest values for RGR and NAR, overall.
\end{abstract}

Key words: competition, interference, weed culture control, growth rate.

1 Recebido para publicação em 11.4.2002 e na forma revisada em 2.4.2003.

Esta pesquisa recebeu apoio financeiro da Fundação de Amparo à Pesquisa do Estado do Rio Grande do Sul (FAPERGS), processo no 00/2660-0.

2 Eng.-Agr., Ph.D., Professor do Departamento de Plantas de Lavoura da Faculdade de Agronomia da Universidade Federal do Rio Grande do Sul - UFRGS, Bolsista do CNPq, Caixa Postal 776, 91501.970 Porto Alegre-RS, <fleck@ufrgs.br>; ${ }^{3}$ Eng.-Agr., Aluno do Programa de Pós-Graduação em Fitotecnia da UFRGS. 


\section{INTRODUÇÃO}

Crescimento vegetal refere-se ao aumento irreversível do volume ocupado pela planta, o qual depende da taxa de divisão e de elongação celular (Taiz \& Zeiger, 1998). Em uma análise teórica, Fischer \& Miles (1973) estabeleceram que o aumento de $50 \%$ na taxa de crescimento radial faz dobrar a habilidade competitiva da planta. Segundo teoria proposta por Grime, citado por Radosevich et al. (1997), uma planta competidora é aquela que possui elevada velocidade de utilização dos recursos do meio, indisponibilizando-os para os seus vizinhos. Assim, uma planta competidora apresenta elevada taxa de crescimento relativo (TCR). Por outro lado, teoria estabelecida por Tilman, citado por Radosevich et al. (1997), postula que plantas competidoras necessitam de menos recursos e, portanto, conseguem sobreviver em ambientes desfavoráveis, ou seja, com baixo aporte de água, nutrientes e/ou luz.

Há considerável variabilidade entre genótipos em termos de velocidade de crescimento tanto da parte aérea quanto da radicular, que pode ser utilizada na seleção de cultivares mais competitivos com plantas daninhas (Altieri \& Liebman, 1988). O rápido crescimento é uma característica importante na determinação do potencial de supressão de uma cultura sobre plantas daninhas (Grundy et al., 1999; Rasmussen \& Rasmussen, 2000).

Características como acúmulo de massa total e de área foliar mostram-se mais importantes na definição das interações de competição entre arroz e Brachiaria brizantha Hochst. Stapf, comparativamente à estatura e ao afilhamento da cultura (Fischer et al., 1995). O genótipo IG10 da espécie Oryza glaberrima foi mais competitivo com Ageratum conyzoides (mentrasto) e Digitaria horizontalis (milhã), em relação aos genótipos de Oryza sativa. Isso foi atribuído, principalmente, à rápida taxa de crescimento relativo (TCR) observada na espécie O. glaberrima, que também apresentou elevada razão de área foliar (RAF) (Johnson et al., 1997, 1998).

No caso do arroz irrigado, a competição pelos recursos água e nutrientes geralmente é pouco expressiva (Gibson et al., 2001). Portanto, características de planta que confiram elevada interceptação de luz favorecem o seu sucesso competitivo. Em arroz, o genótipo M-201 interceptou cinco vezes mais radiação, comparativamente ao genótipo A-301, suprimindo com maior intensidade o crescimento de Echinochloa oryzoides e E. phyllopogon (Gibson et al., 2001). Na presença do genótipo M-201, as infestantes produziram baixa quantidade de diásporos, além de serem controladas de maneira satisfatória com dose reduzida de herbicida.

A interceptação de luz pelo dossel é dependente, além da densidade e do arranjo das plantas, de um conjunto de características morfológicas dos vegetais, como: capacidade de afilhamento, estatura de planta, número de folhas formadas, área foliar, distribuição das folhas, ângulo foliar, decumbência do limbo das folhas e produção de massa aérea (Blackshaw, 1994; Seavers \& Wright, 1999).

Cultivares que apresentam alto investimento em folhas, ou seja, elevada razão de área foliar (RAF), possuem maior potencial de cobertura do solo. A RAF correlaciona-se positivamente com a taxa de crescimento relativa (TCR) e também com a taxa de assimilação líquida (TAL) (Seibert \& Pearce, 1993). Por sua vez, Horak \& Loughin (2000) também observaram associação entre TCR e TAL. A RAF é uma variável morfológica que expressa quanto da massa total é alocada para as folhas da planta. A TCR refere-se ao acúmulo de massa em um determinado intervalo de tempo, por unidade de massa preexistente. Já a TAL representa o acúmulo de massa, também num intervalo de tempo, por unidade de área foliar preexistente, assumindo, portanto, caráter fisiológico (Radosevich et al., 1997).

A hipótese desta pesquisa é de que há variação na velocidade de crescimento e em características de plantas de cultivares de arroz irrigado, e essa variabilidade pode ser utilizada para colocar a cultura em situação competitiva vantajosa. Diante do contexto exposto, o presente trabalho teve como objetivo avaliar variações em características de planta e velocidade de crescimento de cultivares de arroz irrigado sob duas situações de interferência: ausência e presença de plantas concorrentes.

\section{MATERIAL E MÉTODOS}

O experimento foi conduzido durante os meses de novembro a abril da estação estival 
de crescimento de 2000/2001, na Estação Experimental do Arroz (EEA), pertencente ao Instituto Rio-Grandense do Arroz (IRGA), em Cachoeirinha-RS. O preparo do solo foi realizado através do método convencional, compreendendo operações de lavração e de gradagem. Os tratamentos testados foram dispostos segundo o delineamento experimental completamente casualizado, em fatorial $(8 \times 2)$, com quatro repetições. Cada unidade experimental apresentou área total de $4 \mathrm{~m}^{2}(2 \times 2 \mathrm{~m}) \mathrm{e}$ área útil de 2,56 m (1,6 x 1,6 m). Como um dos fatores foram avaliados oito cultivares de arroz: Bluebelle, BRS Ligeirinho, El Paso L 144, IAS 12-9 Formosa, IR 841, IRGA 418, IRGA 421 e XL 6. Esses genótipos foram submetidos a duas situações de interferência - ausência e presença de simuladora de infestação de arrozvermelho, no caso o cultivar de arroz EEA 406, presente na densidade média de 30 plantas $\mathrm{m}$ 2. O cultivar EEA 406 assemelha-se ao arrozvermelho quanto às características de planta.

A densidade de semeadura foi ajustada para cada cultivar com base no poder germinativo das sementes, obtido em laboratório, almejando-se estabelecer densidade de 300 plantas mí. Contudo, a densidade real de plantas alcançada foi de 270 plantas $\mathrm{m}^{-2}$, aproximadamente. Com a utilização dessa simuladora, alcançou-se controle efetivo da densidade, da época de emergência e do arranjo de plantas na área, possibilitando atingir maior controle do erro experimental.

A semeadura foi realizada no dia 18 de novembro de 2000. A simuladora do arroz-vermelho foi semeada em linhas transversais às dos cultivares testados, ambas no espaçamento de $20 \mathrm{~cm}$ entre linhas. As plantas daninhas, presentes espontaneamente na área, foram controladas através da aplicação da mistura em tanque dos herbicidas propanil (2.850 $\mathrm{g}$ ha) $)$, triclopyr (300 $\mathrm{g}$ ha) e quinclorac (200 g hal). Aos 25 dias após a semeadura (DAS) iniciou-se a irrigação da área por inundação, a qual permaneceu no experimento até a colheita dos cultivares. As demais práticas de manejo empregadas no experimento foram fundamentadas nas recomendações técnicas para a cultura do arroz irrigado na região.

Na determinação da velocidade de crescimento dos cultivares, nas duas situações de infestação, foram avaliadas as variáveis: área foliar, estatura de planta e massa seca da parte aérea aos 15, 30, 45 e 60 DAS. Para realização dessas determinações, coletaram-se cinco plantas em cada unidade experimental por época avaliada.

A área foliar foi medida com auxílio de um determinador de área foliar (modelo Area Meter 3100). A estatura das plantas de arroz foi determinada através da mensuração da altura da sua parte aérea, tomando-se o comprimento desde o nível do solo até o ápice delas, com o limbo foliar distendido. Já a massa seca da parte aérea foi avaliada por meio da pesagem das plantas, após estas serem secas em estufa a $65{ }^{\circ} \mathrm{C}$, até atingirem peso constante.

Por intermédio dos dados coletados, calcularam-se as variáveis:

Razão de área foliar (RAF): utilizou-se a equação proposta por Radosevich et al. (1997): $\mathrm{RAF}=\mathrm{A} / \mathrm{M}$, em que: $\mathrm{RAF}=$ razão de área foliar $\left(\mathrm{cm}^{2} \mathrm{mg}^{-1}\right), \mathrm{A}=$ área foliar $\left(\mathrm{cm}^{2} /\right.$ planta $)$ e $\mathrm{M}=$ massa da planta (mg/planta).

Taxa de crescimento relativo (TCR): foi calculada pela equação proposta por Radosevich et al. (1997): $\mathrm{TCR}=(1 / \mathrm{Mi}) .(\mathrm{dM} / \mathrm{dt})$, em que: TCR $=$ taxa de crescimento relativo $\left(\mathrm{mg} \mathrm{dia}^{-1} \mathrm{mg}^{-1}\right)$, $\mathrm{Mi}=$ massa inicial ( $\mathrm{mg} /$ planta $), \mathrm{dM}=$ incremento de massa no intervalo de tempo considerado $(\mathrm{mg} /$ planta $)$ e $\mathrm{dt}=$ intervalo de tempo adotado (dias).

Taxa de assimilação líquida (TAL): foi calculada por equação sugerida por Radosevich et al. (1997): TAL =(1/Ai). (dM/dt), em que TAL $=$ taxa de assimilação líquida $\left(\mathrm{mg}\right.$ dia $\left.^{-1} \mathrm{~cm}^{-2}\right)$, $\mathrm{A} \mathbf{i}=$ área foliar inicial ( $\mathrm{cm}^{2} /$ planta), $\mathrm{dM}=$ incremento de massa no intervalo de tempo considerado ( $\mathrm{mg} /$ planta $)$ e $\mathrm{dt}=$ intervalo de tempo adotado (dias).

Ambas as variáveis, TCR e TAL, podem estar relacionadas à taxa fotossintética e ao conteúdo de clorofila nas folhas. Por isso, aos 50 DAS determinou-se o teor de clorofila no limbo da última folha expandida em cinco plantas de arroz por unidade experimental. Para essa determinação foi utilizado um clorofilômetro, modelo SPAD.

Nos tratamentos livres de plantas da simuladora, foi determinada a cobertura do solo proporcionada pelas plantas de arroz aos 45 e 60 DAS. Essa avaliação foi realizada 
visualmente por duas pessoas, sendo os dados combinados e expressos percentualmente. Aos 70 DAS, determinou-se a penetração de luz no dossel do arroz, utilizando um luxímetro, modelo Licor LAI 2000, com sensor Licor LI-190SA. Mediu-se a radiação acima da comunidade de plantas e, simultaneamente, próximo à superfície do solo. Com esses dados, calculou-se a porcentagem da radiação que penetrou no dossel da cultura. As leituras foram obtidas em torno do meio-dia, quando o ângulo solar era próximo de $90^{\circ}$, perpendicularmente à superfície do solo.

Os dados coletados foram submetidos à análise de variância, através do teste $\mathrm{F}$, e as médias dos tratamentos foram comparadas aplicando-se o teste de Duncan. Em ambas as análises adotou-se o nível de $5 \%$ de probabilidade. Também se realizaram análises de correlação entre as variáveis e de regressão polinomial para incremento de área foliar, estatura de planta e massa da parte aérea das plantas de arroz. Nessa análise foram utilizadas equações de regressão linear, quadrática e exponencial para ajustar os modelos.
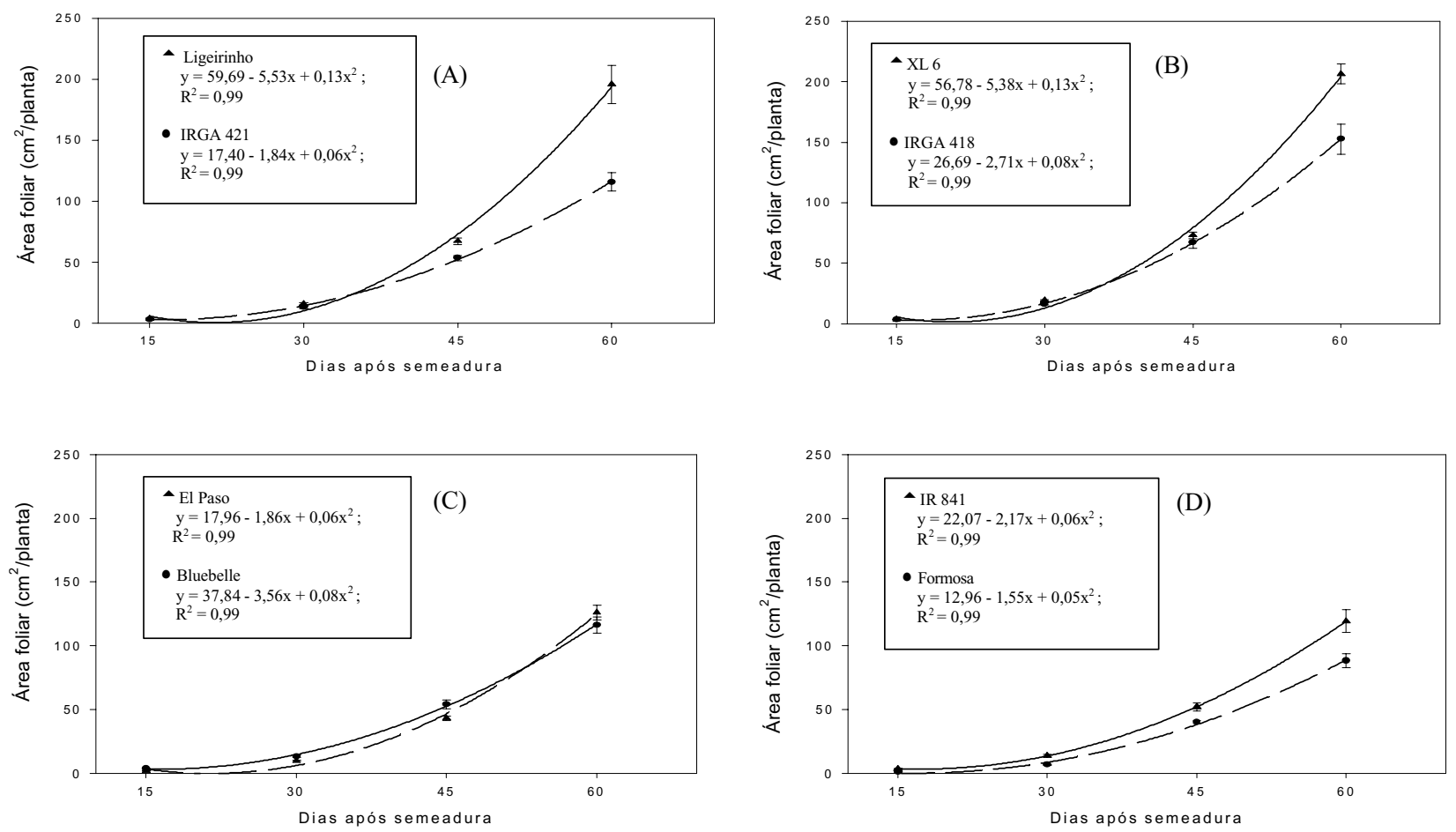

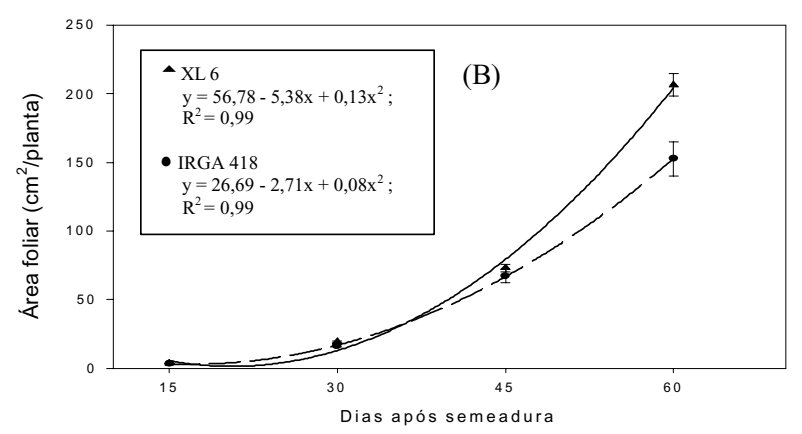

\section{RESULTADOS E DISCUSSÃO}

Houve diferença significativa no incremento de área foliar entre os cultivares investigados (Figura 1). Contudo, o efeito da interação cultivares $x$ condições de infestação não foi significativo para incremento de área foliar das incremento da área das folhas, medido entre 15 e 60 DAS, ajustou adequadamente o modelo quadrático de regressão aos dados, exibindo reduzido acúmulo até os 30 DAS (Figura 1). A partir dessa época a área foliar tendeu a se elevar de maneira acelerada.

Os cultivares Ligeirinho (ciclo superprecoce) e XL 6 (precoce) obtiveram as maiores áreas foliares ao final do período estudado, enquanto o cultivar Formosa (tardia) apresentou o menor acúmulo de área foliar até os 60 DAS (Figura 1). Os demais cultivares apresentaram velocidades de acúmulo de área foliar intermediárias. Destaca-se que, entre os 45 e 60 DAS, ocorreu maior incremento relativo em área foliar para o cultivar El Paso e menor para Bluebelle (Figura 1C). Assim, genótipos que plantas de arroz. Para todos os cultivares, o

Figura 1 - Evolução da área foliar dos cultivares de arroz irrigado Ligeirinho e IRGA 421 (A); XL 6 e IRGA 418 (B); El Paso e Bluebelle (C); e IR 841 e Formosa (D). EEA/IRGA, Cachoeirinha-RS, 2000/01. 
mostram elevada velocidade de acúmulo de área foliar potencialmente podem competir com mais eficiência por luz no início do ciclo, sombreando as plantas vizinhas.

Obtiveram-se correlações significativas ( $\mathrm{r}=$ 0,$78 ; \mathrm{r}=0,75 ; \mathrm{r}=0,53$; e $\mathrm{r}=0,51$ ) entre área foliar medida aos 15, 30, 45 e 60 DAS e cobertura do solo proporcionada pelas plantas de arroz aos 60 DAS. O rápido acúmulo de área foliar proporciona maior habilidade competitiva com plantas daninhas, conforme enfatizado anteriormente por Fischer et al. (1995).

Dentre as características morfológicas, a estatura de planta é a que mais fortemente se relaciona com o baixo crescimento de plantas daninhas, devido ao sombreamento imposto pela cultura, segundo Garrity et al. (1992). No presente estudo, houve diferença significativa de ganho em estatura entre os cultivares avaliados (Figura 2). Para todos eles o incremento em estatura ajustou satisfatoriamente o modelo linear de regressão aos dados (Figura 2).

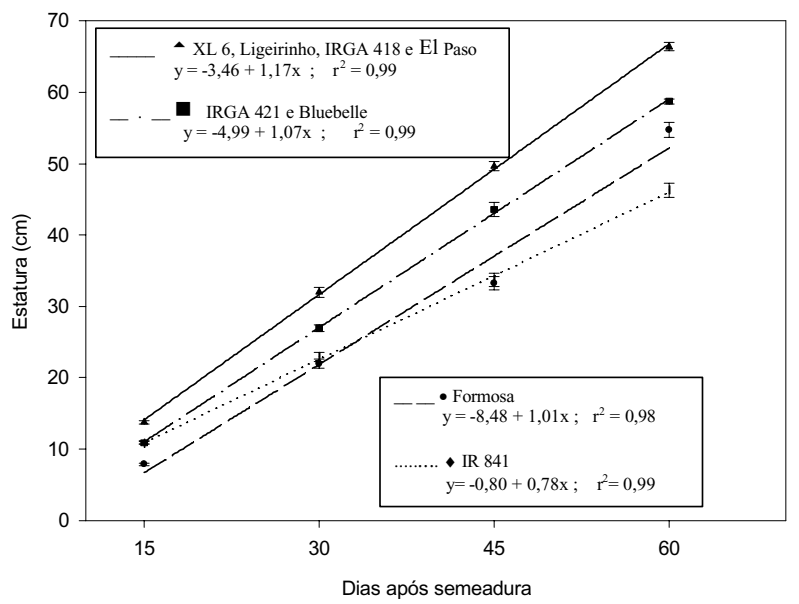

Figura 2 - Evolução da estatura de planta de cultivares de arroz irrigado EEA/IRGA, Cachoeirinha-RS, 2000/01.

Os cultivares XL 6, Ligeirinho, IRGA 418 e El Paso apresentaram elevada velocidade de ganho em estatura até o final do período avaliado (60 DAS), não diferindo entre si (Figura 2). Assim, esses genótipos possuem maior chance de captação de luz em estratos mais elevados do dossel da comunidade de plantas.

Em campo, Brachiaria plantaginea (papuã), por exemplo, leva vantagem na competição com cultivares de arroz irrigado no início do ciclo, devido à maior velocidade de crescimento em estatura que apresenta (Fischer et al., 1995). Por outro lado, até os 30 DAS, o cultivar Formosa mostrou reduzido aumento em estatura, ocupando posição inferior à dos demais cultivares; contudo, a partir dos 30 DAS ele superou o IR 841 (Figura 2). Não se detectou correlação entre ganho em estatura e cobertura do solo proporcionada pelo dossel do arroz aos 45 e 60 DAS (dados não mostrados).

Outra variável importante para caracterizar o crescimento inicial de plantas é o acúmulo de massa. Houve diferenças significativas no incremento de massa da parte aérea entre os cultivares investigados (Figura 3). Novamente, constatou-se não haver interação significativa entre cultivares e infestações no acúmulo de massa até os 60 DAS; por isso, os dados representam ambas as situações de interferência, conjuntamente. Para todas os cultivares investigados, o aumento de massa ajustou o modelo quadrático de regressão, com lento acúmulo até os 30 DAS e posterior aceleração até os 60 DAS (Figura 3). Esse comportamento foi similar ao observado para a variável área foliar.

O cultivar superprecoce Ligeirinho apresentou rápido acúmulo de massa no período estudado (Figura 3A) e, dessa forma, ocupou rapidamente o espaço. Em arroz, foi demonstrado que o acúmulo de massa até o início do afilhamento (35 DAS) é a característica mais importante na definição do potencial supressivo de plantas daninhas pelos cultivares ( $\mathrm{Ni}$ et al., 2000). Em contrapartida, até os 45 DAS, os cultivares Formosa e IR 841 mostraram os menores acúmulos de massa, sendo provável que disponibilizaram maior nicho para ocupação pelas infestantes (Figura 3C). Embora, a partir dos 45 DAS, o cultivar IR 841 apresentasse reduzido acúmulo de massa, ele manteve posição intermediária para acúmulo de área foliar (Figura 1D), demonstrando que investe recursos prioritariamente em formação de folhas. O cultivar híbrido XL 6 demonstrou comportamento semelhante ao de IR 841, pois apresentou incremento mais expressivo em área foliar, comparativamente ao acúmulo de massa (Figura 3B).

Na Tabela 1 constata-se, através do cálculo da razão de área foliar (RAF), que, em todas as avaliações, IR 841 apresentou elevado investimento em folhas. De acordo com Lindquist \& 
Tabela 1 - Razão de área foliar (RAF) $\left(\mathrm{cm}^{2} \mathrm{mg}^{-1}\right)$ de cultivares de arroz irrigado avaliados em quatro épocas. EEA/IRGA, Cachoeirinha-RS, 2000/01

\begin{tabular}{|l|l|l|l|l|}
\hline Cultivar de arroz & $15 \mathrm{DAS}^{\frac{1}{-}}$ & 30 DAS & $45 \mathrm{DAS}$ & $60 \mathrm{DAS}$ \\
\hline IRGA 421 & $0,150 \mathrm{~b}^{-\frac{1}{}}$ & $0,123 \mathrm{ab}$ & $0,116 \mathrm{c}$ & $0,092 \mathrm{c}$ \\
BRS Ligeirinho & $0,180 \mathrm{a}$ & $0,119 \mathrm{~b}$ & $0,110 \mathrm{c}$ & $0,110 \mathrm{c}$ \\
IRGA 418 & $0,144 \mathrm{bc}$ & $0,114 \mathrm{~b}$ & $0,127 \mathrm{bc}$ & $0,113 \mathrm{bc}$ \\
XL 6 & $0,125 \mathrm{~cd}$ & $0,133 \mathrm{a}$ & $0,133 \mathrm{~b}$ & $0,133 \mathrm{~b}$ \\
El Paso L 144 & $0,157 \mathrm{ab}$ & $0,122 \mathrm{ab}$ & $0,125 \mathrm{bc}$ & $0,107 \mathrm{c}$ \\
Bluebelle & $0,153 \mathrm{~b}$ & $0,103 \mathrm{c}$ & $0,112 \mathrm{c}$ & $0,111 \mathrm{c}$ \\
IAS 12-9 Formosa & $0,112 \mathrm{~d}$ & $0,117 \mathrm{~b}$ & $0,124 \mathrm{bc}$ & $0,102 \mathrm{c}$ \\
IR 841 & $0,165 \mathrm{ab}$ & $0,132 \mathrm{a}$ & $0,152 \mathrm{a}$ & $0,162 \mathrm{a}$ \\
\hline Médias & 0,148 & 0,120 & 0,125 & 0,116 \\
CV (\%) & 15,1 & 8,6 & 12,2 & 17,4 \\
\hline
\end{tabular}

${ }^{1 /}$ Dias após a semeadura. ${ }^{2 /}$ Médias seguidas de letras distintas, comparadas nas colunas, diferem entre si pelo teste de Duncan a $5 \%$ de probabilidade.

Mortensen (1998), híbridos de milho que investiram mais em estruturas foliares, no início do ciclo, mostraram maior competitividade com plantas daninhas. Adicionalmente, Horak \& Loughin (2000) observaram que Amaranthus spp. (caruru) apresentaram maior RAF e possuíam maior potencial fotossintético por planta e, também, maior habilidade competitiva. Aos
15 DAS, verificou-se que Ligeirinho e El Paso também apresentaram elevada RAF (Tabela 1). Entre 30 e 60 DAS, XL 6 mostrou, igualmente, possuir elevada canalização de reservas para formação de folhas. O contrário é válido para o cultivar Formosa, que, em geral, apresentou baixos valores de RAF, demonstrando investir menos em folhas do que os demais.

O elevado investimento em folhas, observado no cultivar IR 841 , aliado à reduzida estatura (Figura 2), fez com que ele apresentasse elevada expansão lateral das plantas. Dessa forma, esse genótipo apresentou alta cobertura do solo e, em conseqüência, reduzida penetração de luz no dossel da comunidade (Tabela 2). Em oposição, os cultivares Bluebelle e Formosa, que apresentaram baixas velocidades de crescimento, demonstraram possuir baixa capacidade de cobertura do solo, permitindo elevada penetração de luz no dossel. Nessa situação, a luz que penetra no dossel fica disponível para ser utilizada por plantas daninhas no processo fotossintético. Também se verificou que, aos 60 DAS, o cultivar Ligeirinho, que se destacou por rápido crescimento, propiciou alta
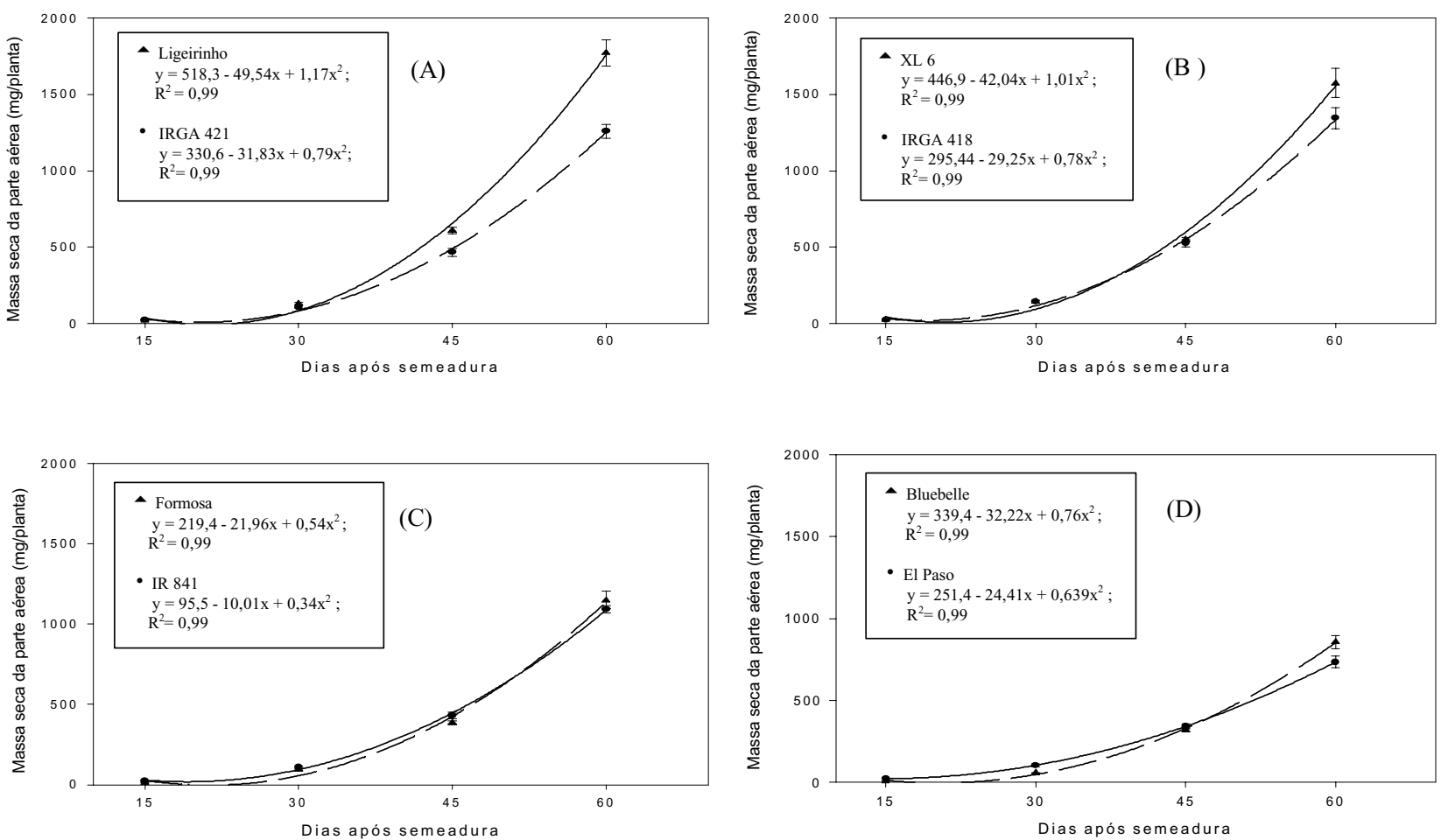

Figura 3 - Acúmulo de massa na parte aérea da planta dos cultivares de arroz irrigado Ligeirinho e IRGA 421 (A); XL 6 e IRGA 418 (B); El Paso e Bluebelle (C); e IR 841 e Formosa (D). EEA/IRGA, Cachoeirinha-RS, 2000/01. 
cobertura do solo, comportamento similar ao observado no cultivar IR 841 (Tabela 2).

Cultivares de trigo que apresentaram maior capacidade de cobertura do solo sombrearam com maior intensidade as plantas daninhas, sendo mais competitivos por luz, em relação aos cultivares com reduzido potencial de sombreamento (Wicks et al., 1986; Seavers \& Wright, 1999), o mesmo ocorrendo em arroz (Gibson et al., 2001).Salienta-se, no entanto, que a capacidade de sombreamento de cultivares varia com as espécies infestantes presentes na área. Para que haja sombreamento de plantas daninhas por culturas, é necessário, além da alta cobertura do solo, elevada estatura de planta, o que possibilita captação de energia luminosa no estrato superior do dossel.
A elevada RAF observada no cultivar IR 841 indica que suas plantas possuem alta área foliar por unidade de massa, o que pode elevar sua capacidade fotossintética. Contudo, o IR 841 apresentou, consistentemente, as menores taxas de crescimento relativo (TCR) e taxas de assimilação líquida (TAL) (Tabela 3). Resultado divergente foi observado por Seibert \& Pearce (1993), que constataram correlação positiva entre RAF, TCR e TAL. Em decorrência, IR 841 demonstrou baixo acúmulo de massa por unidade de massa e de área foliar preexistentes durante os períodos avaliados. É provável que esse comportamento tenha ocorrido em razão do elevado auto-sombreamento, já que o IR 841 manteve patamares médios de área foliar (Figura 1B); entretanto, ele apresentou a menor

Tabela 2 - Cobertura do solo proporcionada por cultivares de arroz irrigado, penetração de luz no dossel e teor de clorofila foliar. EEA/IRGA, Cachoeirinha-RS, 2000/01

\begin{tabular}{|l|c|c|c|c|}
\hline \multicolumn{1}{|c|}{ Cultivar de arroz } & $\begin{array}{c}\text { Cobertura do solo } \\
45 \mathrm{DAS}^{1 /}(\%)\end{array}$ & $\begin{array}{c}\text { Cobertura do solo } \\
60 \mathrm{DAS}(\%)\end{array}$ & $\begin{array}{c}\text { Penetração de luz no } \\
\text { dossel 70 DAS (\%) }\end{array}$ & $\begin{array}{c}\text { Clorofila (SPAD) } \\
50 \mathrm{DAS}\end{array}$ \\
\hline IRGA 421 & $43,1 \mathrm{~b}^{-\frac{1}{2}}$ & $64,2 \mathrm{c}$ & $8,5 \mathrm{~b}$ & $29,5 \mathrm{~b}$ \\
BRS Ligeirinho & $47,6 \mathrm{ab}$ & $77,7 \mathrm{a}$ & $7,4 \mathrm{ab}$ & $29,3 \mathrm{~b}$ \\
IRGA 418 & $46,9 \mathrm{ab}$ & $72,5 \mathrm{~b}$ & $8,0 \mathrm{ab}$ & $32,4 \mathrm{a}$ \\
XL 6 & $47,5 \mathrm{ab}$ & $73,2 \mathrm{~b}$ & $4,9 \mathrm{ab}$ & $29,0 \mathrm{~b}$ \\
El Paso L 144 & $45,5 \mathrm{ab}$ & $71,2 \mathrm{~b}$ & $5,6 \mathrm{ab}$ & $30,0 \mathrm{~b}$ \\
Bluebelle & $37,9 \mathrm{c}$ & $55,7 \mathrm{~d}$ & $12,4 \mathrm{c}$ & $33,4 \mathrm{a}$ \\
IAS 12-9 Formosa & $32,5 \mathrm{~d}$ & $52,0 \mathrm{~d}$ & $13,9 \mathrm{c}$ & $34,4 \mathrm{a}$ \\
IR 841 & $50,6 \mathrm{a}$ & $80,2 \mathrm{a}$ & $4,1 \mathrm{a}$ & $33,2 \mathrm{a}$ \\
\hline Médias & 43,9 & 68,4 & 8,1 & 31,4 \\
CV (\%) & 7,2 & 4,2 & 29,4 & 4,6 \\
\hline
\end{tabular}

${ }^{1 /}$ Dias após a semeadura. ${ }^{2 /}$ Médias seguidas de letras distintas, comparadas nas colunas, diferem entre si pelo teste de Duncan a $5 \%$ de probabilidade.

Tabela 3 - Taxa de crescimento relativo (TCR) $\left(\mathrm{mg} \mathrm{mg}^{-1} \operatorname{dia}^{-1}\right)$ e taxa de assimilação líquida (TAL) $\left(\mathrm{mg} \mathrm{cm}^{-2}\right.$ dia $\left.{ }^{-1}\right) \mathrm{de}$ cultivares de arroz irrigado avaliada em três períodos. EEA/IRGA, Cachoeirinha-RS, 2000/01

\begin{tabular}{|c|c|c|c|c|c|c|}
\hline \multirow{2}{*}{ Cultivares de arroz } & \multicolumn{2}{|c|}{ 15-30 $\mathrm{DAS}^{\underline{1}}$} & \multicolumn{2}{|c|}{ 30-45 DAS } & \multicolumn{2}{|c|}{ 45-60 DAS } \\
\hline & TCR & TAL & TCR & TAL & TCR & TAL \\
\hline IRGA 421 & $0,269 \mathrm{~cd}^{1 /}$ & $1,86 \mathrm{de}$ & $0,231 \mathrm{bc}$ & $1,90 \mathrm{bc}$ & $0,117 \mathrm{a}$ & $1,00 \mathrm{ab}$ \\
\hline BRS Ligeirinho & $0,412 \mathrm{abc}$ & $1,89 \mathrm{cde}$ & $0,246 \mathrm{~b}$ & $2,07 \mathrm{~b}$ & $0,127 \mathrm{a}$ & $1,16 \mathrm{a}$ \\
\hline IRGA 418 & $0,371 \mathrm{ab}$ & $2,60 \mathrm{bc}$ & $0,183 \mathrm{~cd}$ & $1,61 \mathrm{bcd}$ & $0,106 \mathrm{ab}$ & $0,85 \mathrm{~b}$ \\
\hline XL 6 & $0,300 \mathrm{bcd}$ & $2,37 \mathrm{bcd}$ & $0,195 \mathrm{bcd}$ & $1,46 \mathrm{~cd}$ & $0,125 \mathrm{a}$ & $0,96 \mathrm{ab}$ \\
\hline El Paso L 144 & $0,241 \mathrm{~d}$ & $1,56 \mathrm{e}$ & $0,204 \mathrm{bcd}$ & $1,68 \mathrm{bcd}$ & $0,104 \mathrm{ab}$ & $0,84 \mathrm{~b}$ \\
\hline Bluebelle & $0,424 \mathrm{a}$ & $2,83 \mathrm{ab}$ & $0,208 \mathrm{bcd}$ & $2,01 \mathrm{~b}$ & $0,132 \mathrm{a}$ & $1,18 \mathrm{a}$ \\
\hline IAS 12-9 Formosa & $0,358 \mathrm{abc}$ & $3,35 \mathrm{a}$ & $0,313 \mathrm{a}$ & $2,71 \mathrm{a}$ & $0,113 \mathrm{a}$ & $0,91 \mathrm{ab}$ \\
\hline IR 841 & $0,234 \mathrm{~d}$ & $1,50 \mathrm{e}$ & $0,160 \mathrm{~d}$ & $1,23 \mathrm{~d}$ & $0,078 \mathrm{~b}$ & $0,52 \mathrm{c}$ \\
\hline Médias & 0,317 & 2,25 & 0,217 & 1,83 & 0,113 & 0,93 \\
\hline CV $(\%)$ & 28,2 & 30,1 & 25,4 & 26,3 & 27,0 & 27,8 \\
\hline
\end{tabular}

1/ Dias após a semeadura. 르 Médias seguidas de letras distintas, comparadas nas colunas, diferem entre si pelo teste de Duncan a $5 \%$ de probabilidade. 
estatura dentre os cultivares investigados (Figura 2). Dessa forma, deduz-se haver elevada proximidade entre suas folhas, o que propicia auto-sombreamento intenso, com conseqüente redução do potencial fotossintético das folhas do estrato inferior.

Além disso, os valores relativamente baixos de TCR e TAL observados em IR 841 podem estar associados a outras características fisiológicas intrínsecas ao genótipo, como a reduzida adaptação ao ambiente em que foi conduzido o experimento, a baixa atividade de enzimas relacionadas ao processo fotossintético, notadamente rubisco, ou a elevada taxa de respiração para manutenção de processos metabólicos das plantas.

Por outro lado, os cultivares Bluebelle e Formosa destacaram-se por apresentar valores relativamente elevados de TCR e TAL (Tabela 3). Esses cultivares também haviam se destacado por apresentarem baixa velocidade de acúmulo de massa (Figura 3). Uma causa que pode estar associada à elevada velocidade de crescimento relativo é a presença de elevado teor de clorofila, o que foi verificado em folhas de Bluebelle e Formosa, em determinação efetuada aos 50 DAS (Tabela 2).

Verificou-se que cultivares de arroz irrigado apresentam variação em características relativas ao dossel e ao crescimento das plantas. Infestação de 30 plantas $\mathrm{m}^{2}$ do cultivar de arroz EEA 406, simulando a presença de arrozvermelho, não afeta variáveis relativas ao crescimento de cultivares de arroz irrigado. Em geral, os genótipos de arroz Ligeirinho e XL 6 exibem elevadas velocidades de incremento de área foliar, estatura e massa aérea de plantas e, juntamente com IR 841, apresentam elevadas cobertura do solo e interceptação de luz pelo dossel. Em oposição, os cultivares Bluebelle e Formosa mostram características de planta indicativas de baixo potencial competitivo com plantas daninhas.

\section{LITERATURA CITADA}

ALTIERI, M. A.; LIEBMAN, M. Weed management in agroecosystems: ecological approaches. Boca Raton: CRC Press, 1988. $354 \mathrm{p}$.

BLACKSHAW, R. E. Differential competitive ability of winter wheat cultivars against downy brome. Agron. J., v. 86, n. 4, p. 649-654, 1994.
FISCHER, A. et al. Components of early competition between upland rice (Oryza sativa L.) and Brachiaria brizantha (Hochst. ex A.Rich) Stapf. Inter. J. Pest Manag., v. 41, n. 2, p. 100-103, 1995.

FISCHER, R. A.; MILES, R. E. The role of spatial pattern in the competition between crop plants and weeds. A theoretical analysis. Mathem. Biosci., v. 18, p. 335-350, 1973.

GARRITY, D. P.; MOVILLON, M.; MOODY, K. Differential weed suppression ability in upland rice cultivars. Agron. J., v. 84, n. 4, p. 586-591, 1992.

GIBSON, K. D. et al. Water-seeded rice cultivars differ in ability to interfere with watergrass. Agron. J., v. 93, n. 3, p. $326-332,2001$.

GRUNDY, A. C.; BOND, W.; BURSTON, S. Weed suppression by crops. In: THE 1999 BRIGHTON CROP PROTECTION CONFERENCE - WEEDS. Brighton: British Crop Protection Council, 1999. p. 957-962.

HORAK, M. J.; LOUGHIN, T. M. Growth analysis of four Amaranthus species. Weed Sci., v. 48, n. 3, p. 347-355, 2000.

JOHNSON, D. E. et al. The influence of rice plant type on the effect of weed competition on Oryza sativa and Oryza glaberrima. Weed Res., v. 38, n. 3, p. 207-216, 1998.

JOHNSON, D. E. et al. The response of O. glaberrima, $O$. sativa and an interspecific hybrid rice cultivar to weed competition. In: THE 1997 BRIGHTON CROP PROTECTION CONFERENCE - WEEDS. Brighton: British Crop Protection Council, 1997. p. 197-202.

LINDQUIST, J. L.; MORTENSEN, D. A. Tolerance and velvetleaf (Abutilon theophrasti) suppressive ability of two old and two modern corn (Zea mays) hybrids. Weed Sci., v. 46 , n. 5 , p. 569-574, 1998.

NI, H. et al. Oryza sativa plant traits conferring competitive ability against weeds. Weed Sci., v. 48, n. 2, p. 200-204, 2000.

RADOSEVICH, S.; HOLT, J.; GHERSA, C. Weed ecology. 2.ed. New York: Wiley, 1997. 588 p.

RASMUSSEN, K.; RASMUSSEN, J. Barley seed vigour and mechanical weed control. Weed Res., v. 40, n. 2 , p. $219-230,2000$.

SEAVERS, G. P.; WRIGHT, K. J. Crop canopy development and structure influence weed suppression. Weed Res., v. 39, n. 4, p. 319-328, 1999.

SEIBERT, A. C.; PEARCE, R. B. Growth analysis of weed and crop species with reference to seed weight. Weed Sci., v. 41, n. 1, p. $52-56,1993$.

TAIZ, L.; ZEIGER, E. Plant physiology. 2.ed. Sunderland: Sinauern Associates, 1998. 792 p.

WICKS, G. A. et al. Impact of wheat cultivars on establishment and suppression of summer annual weeds. Agron. J., v. 78, n. 1, p. 59-62, 1986. 